\title{
INFLUÊNCIA DA RAZÃO MOLAR ENTRE ÓLEO DE BABAÇU E GLICEROL NA SÍNTESE DE MONOGLICERÍDEOS VIA GLICERÓLISE CONTÍNUA EM REATOR DE LEITO FIXO
}

\author{
R. N. VILAS BÔAS ${ }^{1}$, L. F. TEIXEIRA ${ }^{1}$ e H. F. DE CASTRO ${ }^{1}$ \\ ${ }^{1}$ Escola de Engenharia de Lorena - USP, Departamento de Engenharia Química \\ E-mail para contato: larissa@dequi.eel.usp.br
}

\begin{abstract}
RESUMO - O presente trabalho avaliou a influência da concentração de glicerol na síntese enzimática de monoglicerídeos (MAGs) via glicerólise do óleo de babaçu. As reações foram operadas continuamente em reator de leito fixo, empacotado com lipase de Burkholderia cepacia imobilizada em silica-PVA por 10 dias, contendo óleo: glicerol em diferentes razões molares (1:3, 1:6, 1:9 e 1:12), sob atmosfera inerte e tempo espacial de $6 \mathrm{~h}$. Constatou-se que a síntese de MAGs foi fortemente influenciada pela razão molar dos materiais de partida. Elevadas concentrações de MAGs (em média 33\%) foram obtidas na razão molar de 1:9. Baixas razões favoreceram a formação de diglicerídeos (cerca de 70\%) em detrimento aos MAGs. Provavelmente as baixas razões apresentaram quantidade insuficiente de glicerol para deslocar o equilíbrio da reação para formação de MAGs, enquanto que, a razão molar (1:12) mais elevada propiciou a aderência do glicerol ao suporte da enzima, dificultando a transferência de massa do sistema reacional.
\end{abstract}

\section{INTRODUÇÃO}

A busca por produtos derivados de recursos renováveis, desperta cada vez mais o interesse na área da biotecnologia, principalmente no setor da biotransformação de óleos e gorduras. Aliado a este conceito, o uso de enzimas para modificar a estrutura e a composição dessas matérias-primas lipídicas vem crescendo consideravelmente, devido à versatilidade destes biocatalisadores, mostrando potencial para aplicações na bioconversão de óleos e gorduras para síntese de produtos de interesse industrial, como os monoglicerídeos, biodiesel, lipídios estruturados (Majid e Cheirsilp, 2012).

Monoglicerídeos (MAGs) são surfactantes não-iônico, amplamente utilizado na indústria farmacêutica, de alimentos e indústria de cosméticos, por não apresentarem efeitos colaterais quando ingerido, ou irritação na pele, ao contrário dos surfatantes iônico (Freitas et al., 2008).

Os MAGs são produzidos principalmente por métodos químicos a elevadas temperaturas, na qual possui algumas desvantagens, tais como subprodutos de cor escura e um sabor indesejável. Portanto, em comparação com o processo químico, a síntese de MAGs por catálise enzimática torna-se mais atrativa, pois pode ser realizada eficazmente sob condições suaves, e 
obter um produto específico com maior rendimento e melhor qualidade (Zeng et al., 2010).

Diferentes reações enzimáticas, tais como a alcoólise, esterificação e glicerólise têm sido utilizados para a produção de MAGs. A reação de glicerólise é um processo atrativo, em termos econômico e tecnológico, pois possibilita utilizar o glicerol gerado como subproduto no processamento de biodiesel (Zeng et al., 2010).

$\mathrm{Na}$ síntese de MAG via glicerólise empregando lipase imobilizada, o óleo compreende uma fase hidrofóbica, o glicerol uma fase hidrofílica, e a enzima constitui uma fase sólida. Neste sistema, uma importante inconveniência é a baixa miscibilidade entre os substratos presentes no meio reacional, devido a grande diferença de polaridade entre eles (Pawongrat et al., 2007). No entanto, durante o progresso da reação, os monos e diglicerídeos produzidos podem atuar como emulsionantes das fases hidrofóbica e hidrofílica, melhorando o contato entre os dois substratos e, portanto, aumentando as taxas de conversão. Com base nestas considerações, a reação de glicerólise pode ser realizada empregando apenas glicerol e óleo, como substratos, sem a necessidade de utilizar solventes ou aditivos (Feltes et al., 2013).

Estudos anteriores (Freitas et al., 2009) identificaram a necessidade de grande excesso de glicerol para condução da síntese enzimática de monoglicerídeos em regime descontínuo. Entretanto, em reações conduzidas em fluxo contínuo em reator de leito fixo, verificou-se que uma quantidade excessiva desse álcool (relação molar óleo/glicerol de 1:15) prejudicava a transferência de massa do sistema e causava uma possível aderência do glicerol ao suporte da enzima dificultando o acesso do substrato ao sítio ativo da enzima, resultando numa velocidade de reação mais baixa (Freitas et al., 2010). Desta forma, o presente trabalho teve como objetivo avaliar a influência de diferentes razões molares entre óleo de babaçu e glicerol na síntese enzimática de MAGs via glicerólise do óleo de babaçu conduzidas em fluxo contínuo em reator de leito fixo, utilizando lipase microbiana de Burkholderia cepacia imobilizada em sílica-PVA como catalisador.

\section{MATERIAIS E MÉTODOS}

\subsection{Materiais}

Todos os ensaios foram realizados com uma preparação comercial de lipase de Burkholderia cepacia adquirida na forma de extrato enzimático da Amano Enzyme (Nagoya, Japão) e posteriormente imobilizada em matriz híbrida de sílica-PVA, conforme metodologia descrita por Freitas et al., 2009. Foram preparadas 6 bateladas da lipase imobilizada e os sistemas imobilizados apresentaram uma atividade hidrolítica média de $1900 \pm 120 \mathrm{U} / \mathrm{g}$ e umidade inferior a 10\%. A massa específica do sólido determinada segundo metodologia adotada por Freitas et al. (2010) foi de 1,865 g. $\mathrm{mL}^{-1}$. Como materiais de partida foram utilizados: glicerol (88\%, Merck) e óleo de babaçu refinado adquirido da empresa Mundo dos Óleos (São Paulo-SP) com uma composição aproximada em ácidos graxos de 0,22\% de Ácido Capróico, 3,18\% de Caprílico, 3,21\% de Cáprico, 45,35\% de Láurico, 15,14\% de Mirístico, 0,04\% de Pentadecanóico, 8,37\% de Palmítico, 0,05\% de Palmitoléico, 0,05\% de Margárico, 2,39\% de 
Esteárico, 16,35\% de Oléico, 4,94\% de Linoléico, 0,26\% de Linolênico, 0,15\% de Araquídico, 0,12\% de Eicosenóico, 0,11\% de Behênico, 0,09\% de Lignocérico.

\subsection{Procedimento da reação glicerólise em fluxo contínuo}

As síntese de monoglicerídeos foram realizadas em coluna de vidro encamisada ( $\mathrm{D}=15$ $\mathrm{mm}, \mathrm{L}=55 \mathrm{~mm} \mathrm{e} \mathrm{V}=10 \mathrm{~mL}$ ), conforme esquema experimental ilustrado na Figura 1. A mistura reacional constituída de óleo de babaçu e glicerol em diferentes razões molares (1:3, 1:6, 1:9 e 1:12) foi mantida no frasco de alimentação, sob agitação magnética a $50{ }^{\circ} \mathrm{C}$ e bombeada através do reator de leito fixo em fluxo descendente numa vazão fixa de 1,0 mL.h ${ }^{-1}$ correspondendo a um tempo espacial de 6 horas, calculado de acordo com Levenspiel (2000). A coluna foi empacotada com uma suspensão da lipase imobilizada $(7,0 \mathrm{~g})$ no meio reacional e estabilizada pela recirculação do substrato por um período de $4 \mathrm{~h}$, o que permitiu, também, a eliminação de bolhas de ar formadas durante a etapa do empacotamento da coluna. A atmosfera inerte foi garantida pela inserção de um ponto de $\mathrm{N}_{2}$ no frasco de alimentação, protegendo os substratos da exposição ao ar. Para cada meio de alimentação testado foram quantificados os teores de MAG, DAG e TAG por cromatografia de fase gasosa durante 10 dias de operação do sistema experimental.

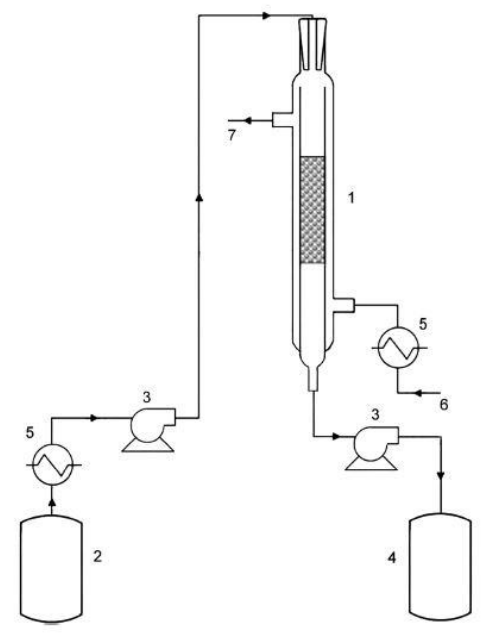

Figura 1 - Esquema experimental do reator de leito fixo: 1 - biorreator; 2 - reservatório de alimentação; 3 - bombas peristálticas; 4 - saída do produto; 5 - banho para controle de temperatura; 6 - entrada de água; 7 - saída de água.

\subsection{Métodos de Análises}

$\underline{\text { Análise cromatográfica para dosagem de monoglicerídeos }}$

As concentrações de monos, dis e triglicerídeos foram determinadas por cromatografia de fase gasosa, utilizando-se uma coluna capilar (CPSil 5CB: $10 \mathrm{~m}$ x 0,25 mm x 0,12 $\mu \mathrm{m}$, Varian), temperaturas do detector e injetor de $300^{\circ} \mathrm{C}$, fluxo da coluna de $2 \mathrm{~mL} / \mathrm{min}$ (o gás de arraste utilizado foi o nitrogênio), pressão da coluna de 10 psi, split de 1:20, atenuação $=1$, temperatura 
de $80^{\circ} \mathrm{C}$ no momento da injeção, variando-se a rampa de aquecimento para cada método de análise de acordo com a metodologia descrita por Freitas et al. (2009).

\section{Cálculo de Produtividade}

Os valores de produtividade obtidos nas glicerólises do óleo de babaçu foram determinados empregando-se a Equação 1.

$$
P=\frac{C}{\tau}
$$

em que: $P=$ é a produtividade $\left(\mathrm{mg}_{\mathrm{MAGs}} / \mathrm{g}_{\text {amostra. }}\right.$ ), $C=$ é a concentração em $\mathrm{mg}$ de MAGs por grama de amostra, $\tau=$ é o tempo espacial da reação $(\mathrm{h})$.

\section{Cálculo de Seletividade}

Os valores de seletividade obtidos nas glicerólises do óleo de babaçu foram determinados empregando-se a Equação 2.

$$
\% \text { Seletividade }=\frac{\% M A G}{\% M A G+\% D A G+\% T A G}
$$

em que: \% MAG = é a quantidade de monoglicerídeos formada na reação, \% DAG = é a quantidade de diglicerídeos formada na reação e \% TAG é a quantidade de triglicerídeos não convertidos na reação.

\section{RESULTADOS E DISCUSSÃO}

Como a reção de glicerólise catalisada por lipase imobilizada consiste em um sistema de três fases (óleo, glicerol e enzima), a miscibilidade do meio reacional, essencial para uma catálise enzimática eficaz, é um dos obstáculos a ser superado no processo. Além disso, sabe-se que para deslocar o equilíbrio da glicerólise no sentido da formação de monoglicerídeos, deve-se aumentar a concentração de glicerol, ou seja, utilizar excesso desse álcool.

Nesse contexto, visando estabelecer maior homogeneidade do meio reacional e alcançar maiores rendimentos de MAGs, foram realizados testes contínuos em reator de leito fixo, variando-se a razão molar entre óleo:glicerol de 1:3, 1:6, 1:9 e 1:12, sob atmosfera inerte. Os resultados obtidos são ilustrados nas Figuras 2 e 3. 


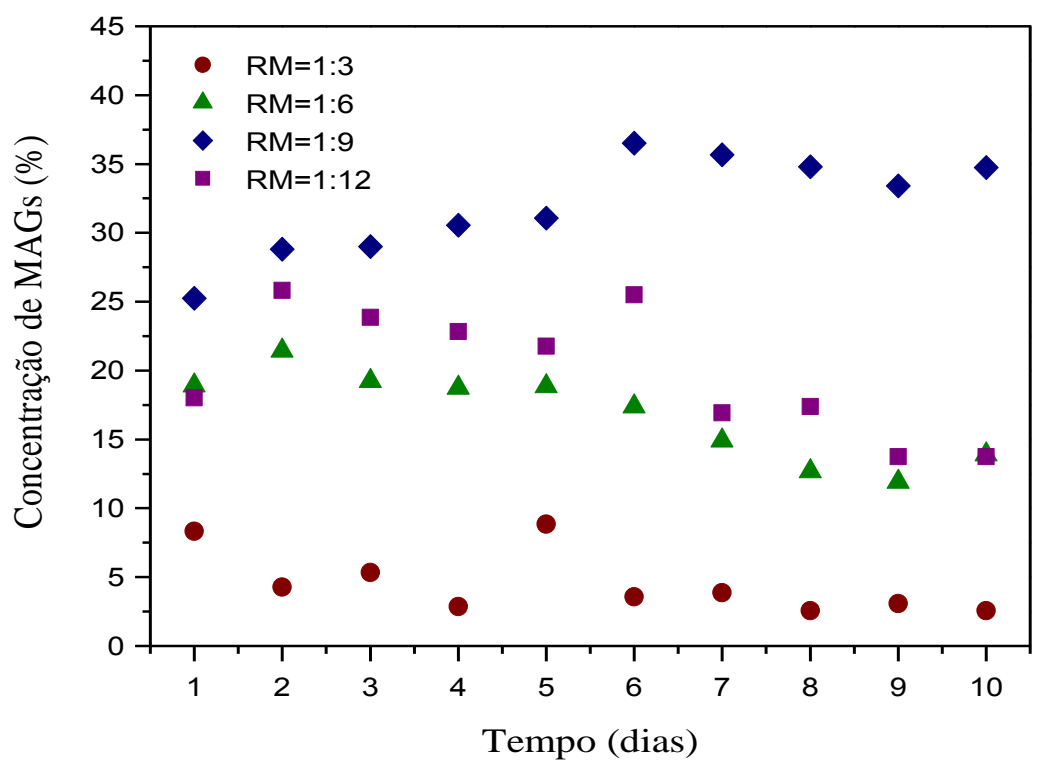

Figura 2 - Formação de monoglicerídeos nas glicerólises contínuas do óleo de babaçu empregando diferentes razões molares (Razão molar $=1: 3$ (óleo/glicerol), Razão molar $=1: 6$ (óleo/glicerol), Razão molar = 1:9 (óleo/glicerol), Razão molar =1:12 (óleo/glicerol), temperatura $50{ }^{\circ} \mathrm{C}$ e tempo espacial de $\left.6 \mathrm{~h}\right)$.

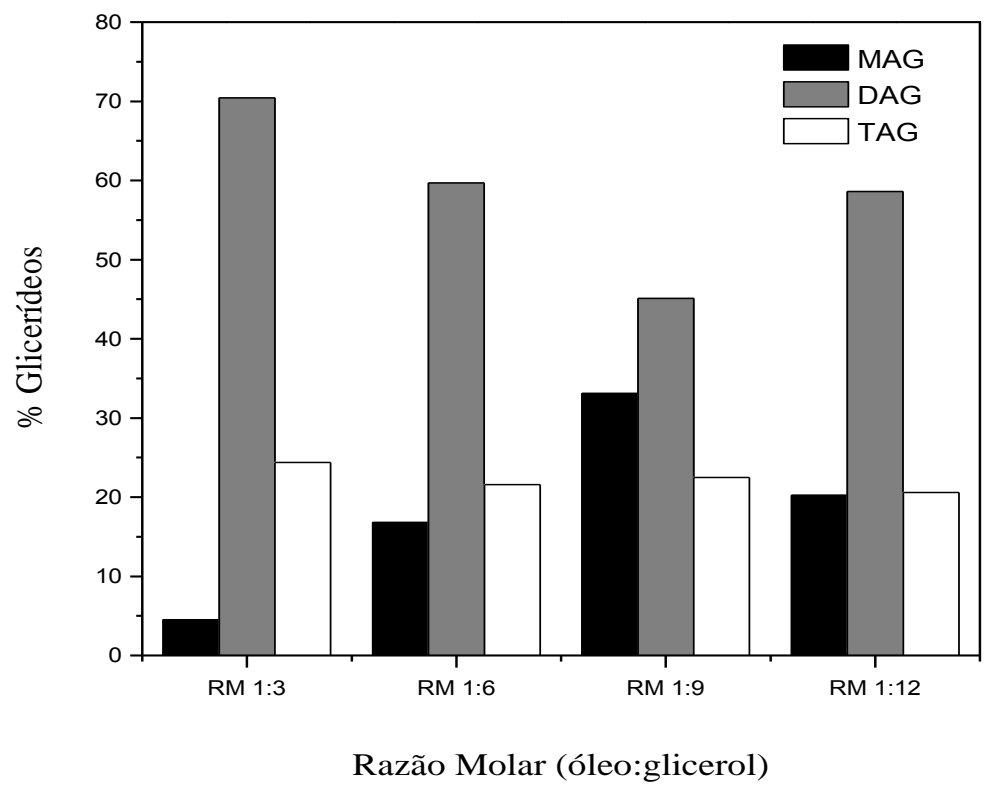

Figura 3 - Formação média de monoglicerídeos e diglicerídeos e consumo de triglicerídeos nas glicerólises contínuas do óleo de babaçu empregando diferentes razões molares. 
De acordo com os dados apresentados na Figura 2, constata-se que a síntese de MAGs foi fortemente influenciada pela razão molar dos materiais de partida. Observa-se que em todos os testes realizados, independentemente da proporção dos materiais de partida, houve produção de MAGs, apresentando formação média de 4,5 $\pm 2,3 \%, 16,8 \pm 3,2 \%, 33,1 \pm 0,9 \%$ e 20,2 $\pm 4,4 \%$, quando se empregou razões molares de 1:3, 1:6, 1:9 e 1:12, respectivamente. As baixas formações de MAGs constatadas para substratos contendo razões molares de 1:3 e 1:6 podem ser creditadas a quantidade insuficiente de glicerol no meio reacional para deslocar o equilíbrio da reação para formação do produto desejado.

Por outro lado, o rendimento em MAGs foi claramente favorecido pelo aumento da razão molar de óleo:glicerol, resultando na formação de cerca de 33\% empregando razão molar de óleo:glicerol de 1:9. Além disso, nessa reação foi verificado que o sistema experimental mantevese estável sem grandes oscilações, confirmando que o excesso do álcool favorece a formação dos monoglicerídeos como constatado em reações conduzidas em regime descontínuo (Freitas et al, 2009). Esse resultado pode ser justificado pela melhor homogeneidade do meio reacional, reduzindo os problemas de transferência de massa do substrato e consequentemente, facilitando a ação da lipase na interface polar-apolar (Martinelle et al., 1995). Entretanto, quando se utilizou uma razão molar mais elevada (1:12) houve um decréscimo na formação de MAGs (20\%). Dois fatores podem estar relacionados a estes resultados: i) a homogeneidade do meio reacional e ii) a possível aderência do glicerol ao suporte da enzima (Kruger et al., 2011). Ambos os fatores podem ter dificultado a transferência de massa do sistema reacional, acarretando a ineficiência da catálise enzimática, ou seja, o excesso de glicerol no meio reacional dificultou o acesso do substrato ao sítio ativo da enzima, resultando numa velocidade de reação mais baixa, conforme relatado por Valério 2009.

Na Figura 3, pode-se observar que o rendimento de DAGs foi maior para menores razões entre óleo:glicerol, visto que $70 \%$ desse acilglicerol foi obtido na razão molar de 1:3, sugerindo a ocorrência de desvio da rota enzimática favorecendo a formação de DAGs em detrimento aos MAGs. Esta evidência corrobora com os resultados descritos por Cheirsilp et al. (2007), que demonstraram que baixas concentrações de glicerol fornecem altas taxas de produção de diglicerídeos, mas baixos rendimentos de monoglicerídeos. Além disso, verifica-se que não é necessário um grande excesso de glicerol para deslocar o equilíbrio da glicerólise no sentido da formação de monoglicerídeos, visto que uma variação significativa na formação do produto desejado foi observada quando se empregou razões molares intermediárias.

A Tabela 1 mostra a influência das diferentes razões molares entre o óleo e glicerol na seletividade e produtividade para formação de monoglicerídeos. É possível observar que a razão molar que apresentou a maior formação de MAGs (1:9), também foi a que apresentou o valor mais elevado de seletividade, atingindo $33,10 \%$, e produtividade de $55,17 \mathrm{mg}_{\text {MAGs }} / \mathrm{g}_{\text {amostra. }}$. h para a formação desse glicerídeo, comprovando a eficácia dessa condição experimental. 
Tabela 1 - Seletividade, produtividade e formação de monoglicerídeos (MAGs) nas reações de glicerólises contínuas do óleo de babaçu empregando diferentes razões molares

\begin{tabular}{cccc}
\hline $\begin{array}{c}\text { Razão Molar } \\
\text { óleo:glicerol }\end{array}$ & $\begin{array}{c}\text { Formação de } \\
\text { MAGs }(\boldsymbol{\%})\end{array}$ & $\begin{array}{c}\text { Seletividade } \\
\mathbf{( \% )}\end{array}$ & $\begin{array}{c}\text { Produtividade } \\
\left(\mathbf{m g}_{\text {MAGs }} / \mathbf{g}_{\text {amostra.h }}\right)\end{array}$ \\
\hline RM 1:3 & 4,52 & 4,52 & 7,53 \\
RM 1:6 & 16,80 & 16,80 & 28,00 \\
RM 1:9 & 33,10 & 33,10 & 55,17 \\
RM 1:12 & 20,24 & 20,24 & 33,73 \\
\hline
\end{tabular}

\section{CONCLUSÃO}

Pode-se concluir que a relação molar entre óleo e glicerol é um fator seletivo para as reações de glicerólises enzimáticas, na qual valores mais elevados de glicerol favorecem a formação de MAGs, enquanto valores mais baixos favorecem a formação de DAGs. Estes resultados podem ser fundamentados na capacidade do glicerol em deslocar o equilíbrio da reação, favorecendo um determinado produto, pela homogeneidade do sistema reacional e pelos fenômenos causados pela aderência do glicerol no suporte da enzima. No presente trabalho, o melhor desempenho foi obtido empregando razão molar intermediária (1:9), atingindo 33\% de MAGs, $33,10 \%$ de seletividade e produtividade de $55,17 \mathrm{mg}_{\text {MAGs }} / \mathrm{g}_{\text {amostra }} \cdot \mathrm{h}$, o que apresenta vantagens econômicas ao processo, como a redução da quantidade de reagente além de facilitar a etapa de purificação do produto.

\section{REFERÊNCIAS}

CHEIRSILP, B.; KAEWTHONG, W.; H-KITTIKUN, A. Kinetic study of glycerolysis of palm olein for monoacylglycerol production by immobilized lipase. Biochem. Eng. J., 35, n.1, p. 71$80,2007$.

FELTES, M. M. C.; OLIVEIRA, D.; BLOCK, J. M.; NINOW, J. L. The production, benefits, and applications of monoacylglycerols and diacylglycerols of nutritional interest. Food Bioprocess Technol, v. 6, p. 17-35, 2013.

FREITAS, L.; BUENO, T.; PEREZ, V. H.; CASTRO, H. F. Monoglicerídeos: produção por via enzimática e algumas aplicações. Química Nova, v. 31, n. 6, p. 1514-1521, 2008.

FREITAS, L.; DA RÓS, P. C. M.; SANTOS, J. C.; DE CASTRO, H. F. An integrated approach to produce biodiesel and monoglycerides by enzymatic interestification of babassu oil (Orbinya sp). Process Biochem., v. 44, n. 10, p. 1068-1074, 2009.

FREITAS, L.; SANTOS, J.C.; ZANIN, G.M.; DE CASTRO, H.F. Packed-bed reactor running on babassu oil and glycerol to produce monoglycerides by enzymatic route using immobilized Burkholderia cepacia lipase. Applied Biochemistry and Biotechnology, v. 161, p. 372-381, 2010. 
KRUGER, R. L.; SYCHOSKI, M.; BALEN, M.; NINOW, J. L.; CORAZZA, M. L. Estudo da glicerólise enzimática na produção de mono e diacilgliceróis utilizando óleo de oliva. Rev. C. Ex. e Nat., v. 13, n. 3, p. 331-351, 2011.

LEVENSPIEL, O. Engenharia das Reações Químicas. São Paulo: Edgard Blucher, 2000. Cap. 5, p. 74-98.

MAJID, N.; CHEIRSILP, B. Optimal conditions for the production of monoacylglycerol from crude palm oil by an enzymatic glycerolysis reaction and recovery of carotenoids from the reaction product. International Journal of Food Science and Technology, v. 47, p. 793-800, 2012.

MARTINELLE M, HOLMQUIST M, HULT K. On the interfacial activation of Candida antarctica lipase A and B as compared with Humicola lanuginosa lipase. Biochimica et Biophysica Acta-Lipids and Lipid Metabolism, v. 1258, n. 3, p. 272-276, 1995.

PAWONGRAT, R.; XU, X.; H-KITTIKUN, A. Synthesis of monoacylglycerol rich in polyunsaturated fatty acids from tuna oil with immobilized lipase AK. Food Chemistry, v. 104, p. 251-258, 2007.

VALÉRIO, A. Glicerólise enzimática de óleo de oliva utilizando surfactantes food grade em sistemas livre de solvente. Dissertação de Mestrado - Departamento de Engenharia de Alimentos, URI - Campus de Erechim, 2009.

ZENG, F.; YANG, B.; WANG, Y.; WANG, W.; NING, Z.; LI, L. Enzymatic production of monoacylglycerols with camellia oil by the glycerolysis reaction. J. Am. Oi.l Chem. Soc., v. 87, p. 531-537, 2010. 